\title{
Effort-reward imbalance at work, over-commitment personality and diet quality in Central and Eastern European populations
}

\author{
Sung-Wei Chen ${ }^{1,2}$, Anne Peasey ${ }^{1}$, Denes Stefler ${ }^{1}$, Sofia Malyutina ${ }^{3}$, Andrzej Pajak ${ }^{4}$, Ruzena Kubinova ${ }^{5}$, \\ Jen-Hui Chan ${ }^{2}$, Martin Bobak ${ }^{1}$ and Hynek Pikhart ${ }^{1}{ }^{1}$ \\ ${ }^{1}$ Department of Epidemiology and Public Health, University College London, London WC1E 6BT, UK \\ ${ }^{2}$ Department of Psychiatry, National Taiwan University Hospital, Hsinchu Branch, Hsinchu City 300, Taiwan \\ ${ }^{3}$ Institute of Internal and Preventive Medicine, Siberian Branch of the Russian Academy of Medical Sciences, Novosibirsk \\ 630090, Russia \\ ${ }^{4}$ Department of Epidemiology and Population Sciences, Jagiellonian University Medical College, Krakow 31531, Poland \\ ${ }^{5}$ Department of Environmental Health Monitoring System, National Institute of Public Health, Prague 10042, Czech Republic
}

(Submitted 14 July 2015 - Final revision received 10 November 2015 - Accepted 22 December 2015 - First published online 12 February 2016)

\section{Abstract}

The aims of this study were to investigate the associations between work stress defined by the effort-reward imbalance (ERI) model and diet quality and to examine the potential role of over-commitment (OC) personality in ERI-diet relationships. A cross-sectional study was conducted in random population samples of 6340 men and 5792 women (age 45-69 years) from the Czech Republic, Russia and Poland. Dietary data were collected using FFQ. The healthy diet indicator (HDI) was constructed using eight nutrient/food intakes (HDI components) to reflect the adherence to WHO dietary guideline. The extent of imbalance between effort and reward was measured by the effort:reward (ER) ratio; the effort score was the numerator and the reward score was multiplied by a factor adjusting for unequal number of items in the denominator. Logistic regression and linear regression were used to assess the associations between exposures (ER ratio and OC) and outcomes (HDI components and HDI) after adjustment for confounders and mediators. The results showed that high ER ratio and high OC were significantly associated with unhealthy diet quality. For a 1 -SD increase in the ER ratio, HDI was reduced by 0.030 and 0.033 SD in men and women, and for a 1-SD increase in OC, HDI was decreased by 0.036 and $0.032 \mathrm{sD}$ in men and women, respectively. The modifying role of OC in ERI-diet relationships was non-significant. To improve diet quality at workplace, a multiple-level approach combining organisational intervention for work stress and individual intervention for vulnerable personality is recommended.

\section{Key·words: Diet: Effort-reward imbalance: Work stress: Over-commitment: Personality}

Health behaviours such as unhealthy diet, alcohol drinking, smoking and physical inactivity have been found to increase risks of chronic diseases ${ }^{(1)}$. High intakes of SFA and cholesterol are associated with high levels of LDL fraction of cholesterol and TAG, which increase risks of $\mathrm{CHD}$ and atherosclerosis. In contrast, high intakes of fruits and vegetables reduce risks of $\mathrm{CHD}$, stroke, hypertension, diabetes and cancer ${ }^{(2)}$. Diet quality is defined by the adherence to dietary guidelines associated with health outcomes such as chronic diseases ${ }^{(3)}$. Diet is influenced by a wide range of psychosocial factors; in particular, chronic stress was found to influence individual psychological and physiological responses, resulting in food choice towards high-fat and high-carbohydrate content ${ }^{(4)}$.

Work stress, a common type of chronic stress in adults, has been measured comprehensively after theoretical development of the demand-control (DC) model and the effort-reward imbalance (ERI) model. The DC model proposes that job task profiles defined by low control and high demand (job strain) may elicit sustained stress reactions. Job strain was found to predict unhealthy $\operatorname{diet}^{(5-8)}$, as well as other health behaviours such as drinking, smoking and physical inactivity ${ }^{(9-11)}$.

In the ERI model, work stress is defined by the violation of social reciprocity in terms of high extrinsic effort (heavy workload, interruption, responsibility, overtime, physical demands and increasing demands) and low reward (salary, esteem, promotion prospect and job security). The ERI model has been found to predict obesity, high blood cholesterol, hypertension, diabetes and $\mathrm{CVD}^{(12-14)}$. ERI is suggested to influence the above-mentioned chronic diseases through psychobiological processes (autonomic, endocrine and immune activation) and health behaviours ${ }^{(15)}$. There have been empirical studies showing that high ER ratio predicted health

Abbreviations: CEE, Central and Eastern European; ERI, effort-reward imbalance; HAPIEE, Health, Alcohol and Psychosocial factors In Eastern Europe; HDI, healthy diet indicator; OC, over-commitment.

* Corresponding author: Dr H. Pikhart, fax +44 2078 130280, email epidemucl33@gmail.com 
behaviours - drinking, smoking and physical inactivity ${ }^{(16-18)}$ but evidence for the link between ERI and diet is lacking. As mentioned earlier, evidence shows that unhealthy diet increases risks of chronic diseases; diet may mediate the impacts of ERI on chronic diseases. Thus, it is plausible to suggest a potential link between ERI and diet.

The ERI model incorporated a personality construct over-commitment (OC) - thereby enabling examination of the potential role of personality in work stress-outcome relationships. OC reflects a cognitive motivational pattern of coping with demands characterised by high need for control, excessive striving at work and inability to withdraw from work; high OC persons tend to maintain excessive effort under inadequate reward ${ }^{(19)}$. The concept of $\mathrm{OC}$ is similar to 'workaholism' - being overly concerned about work, to be driven by strong and uncontrollable work motivation and to spend so much energy and effort into work that it impairs relationships, leisure activities and health ${ }^{(20)}$.

OC was primarily assumed to have a main effect on health outcomes (high OC increases the risk of poor health) or a modifying effect on ERI-Outcome relations (those with high ERI and high OC have an even higher risk of poor health). A review of forty-five studies found that the main effect of OC was supported in seventeen out of twenty-seven studies (63\%), but the modifying effect was supported in only three out of twelve studies $(25 \%)^{(13)}$. However, very few studies have examined the potential role of OC in relationships between ERI and health behaviours. Two studies reported negative findings on the main effect of OC on smoking, without testing the modifying effect of $\mathrm{OC}^{(21,22)}$.

On the basis of identified research gaps, the aims of this study were as follows: (1) to investigate the associations between ERI and diet quality in the Central and Eastern European (CEE) populations, and (2) to examine the potential role of OC personality in ERI-diet relationships. In CEE countries, diet is characterised by high consumption of SFA and sugar but low intake of fruits and vegetables ${ }^{(23)}$. Diet is suggested to increase risks for chronic diseases, contributing to mortality gap between Western Europe and $\mathrm{CEE}^{(24)}$. Since 1989, changing working environments in CEE have resulted in the highest levels of job insecurity among European countries ${ }^{(25)}$. Work stress has been found to predict CVD, poor health and high alcohol consumption in $\mathrm{CEE}^{(26-28)}$. Thus, this context of socio-economic transformation provides a natural setting in which to examine the relationships between work stress, personality and diet; the results are expected to contribute to the deeper understanding of the potential mechanisms via which work stress influences chronic diseases.

\section{Methods}

\section{Study design and population}

The data were obtained from the Health, Alcohol and Psychosocial factors In Eastern Europe (HAPIEE) study. Random samples of 45-69-year-old men and women were selected from population registers in six towns (Havízov/Karviná, Jihlava, Ústí nad Labem, Liberec, Hradec Králové and Kromezíz) in the Czech Republic,
Krakow in Poland and Novosibirsk in Russia from 2002 to 2005. From 28947 subjects recruited (overall response rate 61\%), ineligible people - that is, retired (14060), unemployed (1178) and housewives (307) - were excluded. Next, those with missing values in employed status (131), exposure variables (518) and dietary outcomes (621) were excluded; in addition, subjects with missing values for more than fifteen items in the FFQ were excluded. The final sample consisted of 12132 subjects (6340 men and 5792 women).

Each participant independently completed a structured questionnaire and had a medical examination. This study was conducted according to the guidelines laid down in the Declaration of Helsinki, and all procedures involving human subjects were approved by the ethical committees of University College London and all three countries. Written informed consent was obtained from all the subjects. The methodology of the HAPIEE study was described in detail by Peasey et al. ${ }^{(29)}$.

\section{Dietary outcomes}

Dietary data were collected using the FFQ adapted from Willett et al. ${ }^{(30)}$ and used previously in the Whitehall II Study. Owing to inclusion of country-specific dishes, the Czech, Polish and Russian FFQ consisted of 136, 148 and 147 food items, respectively. For each food item, a country-specific portion size was specified and its nutrient content was based on the McCance and Widdowson food composition data and local food composition tables ${ }^{(31)}$. Subjects were asked how often they had consumed that particular amount of the item during the last 3 months, with nine responses ranging from 'never or less than once per month' to ' 6 or more times/d'. Daily intakes of nutrients were calculated by multiplying the frequency of food consumed per day with the nutrient content of the specified portion size. This methodology was described in detail by Boylan et al. ${ }^{(23)}$.

Healthy diet indicator (HDI), a diet quality score, was constructed to reflect the adherence to the World Health Organization $^{(32)}$ dietary guideline for the prevention of chronic diseases (2003). Huijbregts et al. $^{(33)}$ developed this approach to identify diet quality associated with chronic diseases. According to the WHO guideline, eight nutrient or food intakes were selected: (1) percentages of total energy intakes, without energy provided by alcohol (as alcohol consumption differed considerably between countries), from SFA, PUFA, proteins, total carbohydrates and free sugar; (2) nutrient intakes of NSP and cholesterol; (3) and food intakes of fruits and vegetables. Next, a dichotomous variable was generated for each nutrient or food intake; if one's intake was within the WHO-recommended range, then this variable was coded as 1 (healthy intake), otherwise it was coded as 0 (unhealthy intake). The HDI score was the sum of eight dichotomous variables (HDI components), and thus each subject has a score value ranging from 0 to 8 (Table 1 ).

MUFA was not included because the WHO guidelines did not take them into account. Sodium chloride was not included, as only information on the $\mathrm{Na}$ content of foods was available, but unknown amount of salt was added during preparation of meals or at the table. 
Table 1. Eight components of HDI

\begin{tabular}{lll}
\hline & \multicolumn{2}{c}{ Dichotomous value } \\
\cline { 2 - 3 } $\begin{array}{ll}\text { Individual HDI component } \\
\text { Nutrient or food intakes }\end{array}$ & $1=$ within WHO-suggested range & $0=$ otherwise \\
\hline 1. SFA & $1=<10 \%$ of total energy & $0=>10 \%$ of total energy \\
2. PUFA & $1=6-10 \%$ of total energy & $0=<6 \%$ or $>10 \%$ of total energy \\
3. Protein & $1=10-15 \%$ of total energy & $0=<10 \%$ or $>15 \%$ of total energy \\
4. Total carbohydrate & $1=55-75 \%$ of total energy & $0=<55 \%$ or $>75 \%$ of total energy \\
5. Free sugars & $1=<10 \%$ of total energy & $0=>10 \%$ of total energy \\
6. NSP & $1=>20 \mathrm{~g} / \mathrm{d}$ & $0=<20 \mathrm{~g} / \mathrm{d}$ \\
7. Cholesterol & $1=<300 \mathrm{mg} / \mathrm{d}$ & $0=>300 \mathrm{mg} / \mathrm{d}$ \\
8. Fruit and vegetable & $1=>400 \mathrm{~g} / \mathrm{d}$ & $0=<400 \mathrm{~g} / \mathrm{d}$ \\
\hline
\end{tabular}

HDI, healthy diet indicator.

\section{Exposure variables}

The ERI model is operationalised as a standardised self-report measure containing twenty-three items, defining three unidimensional scales: extrinsic effort, reward and OC, with each item rated on a five-point (extrinsic effort and reward) or four-point (OC) scale. Extrinsic effort was measured using six items on demanding aspects of the work environment: quantitative load, qualitative load, physical load and increasing load. Reward was assessed using eleven items on financial reward, esteem reward, promotion prospect and job security ${ }^{(19)}$. The extent of imbalance between extrinsic effort and reward was measured by the effort:reward (ER) ratio: extrinsic effort score was the numerator, and reward score was multiplied by a correction factor $(6 / 11)$ adjusting for unequal number of items in the denominator. The ERI questionnaire was translated into all three languages, back-translated to confirm accuracy of original translations and validated in the pilot of HAPIEE study ${ }^{(34)}$.

OC was assessed using six items and its score was created by summing them up: (1) 'I get easily overwhelmed by time pressures at work'; (2) 'As soon as I get up in the morning I start thinking about work problems'; (3) 'When I get home, I can easily relax and switch off work'; (4) 'People close to me say I sacrifice too much for my job'; (5) 'Work is still on my mind when I go to bed'; (6) and 'If I postpone something that I was supposed to do today, I have trouble sleeping at night'.

\section{Potential confounders}

A variable was considered a confounder if it met the following three criteria: it must be a risk factor for the outcome; it must be associated with the exposure in the study population; and it cannot be a mediator in the causal path between the exposure and the outcome ${ }^{(35)}$. Potential confounders were selected from the HAPIEE study if they were known risk factors for poor diet: demographics (age and marital status) and socio-economic indicators (educational level, occupational class and deprivation $)^{(36)}$. These variables were significantly $(P<0.05)$ associated with at least one exposure variable.

The age of the subjects ranged from 45 to 69 years at baseline. Marital status was coded as follows: (1) married or cohabiting, (2) single and (3) divorced or widowed. Educational status was categorised as follows: (1) primary or less, (2) vocational, (3) secondary and (4) university. Occupational grade was categorised as follows: (1) manager or professional, (2) non-manual workers and (3) manual workers. Material deprivation was assessed using three questions on how often the subject's household had difficulties to buy enough food or clothes and to pay bills for electricity, heating and housing. The answers to each question were coded from 'never' (0) to 'always' (3). Deprivation score, the sum of three responses, ranged from 0 to 9, and was dichotomised into low (0-3.9) and high (4-9).

\section{Potential mediators}

Potential mediators (depression, problem drinking and current smoking) in the causal path between the exposure and the outcome were selected from the HAPIEE study. Existing evidence shows that ERI can predict depression ${ }^{(34)}$, alcohol drinking $^{(16)}$ and smoking ${ }^{(17)}$, all of which may influence diet. Depression is associated with low motivation for planning and eating a healthy diet, decreased appetite or over-eating ${ }^{(37)}$. High alcohol consumption results in restraint from eating or over-eating $^{(38)}$. Although smoking suppresses appetite temporarily, smokers tend to consume more SFA, more sugars and less fruits and vegetables ${ }^{(39)}$.

Depressive symptoms were measured using the Center for Epidemiologic Studies Depression scale (CESD), consisting of twenty self-reported items that ranged from 0 to $60 ; \mathrm{CESD} \geq 16$ was defined as having clinically relevant depressive symptoms ${ }^{(40)}$. Problem drinking was screened using the CAGE questionnaire consisting of four items with two responses $(0=$ no, $1=$ yes $)$. With a cut-off point of 2 , sensitivity and specificity were high in relation to alcohol abuse and dependence ${ }^{(41)}$. Smoking status was measured by the question: 'Do you smoke cigarettes?'. Those with the first two answers (yes, regularly, at least one cigarette a day; or yes, occasionally, less than one cigarette a day) were classified as current smokers; others (no, I smoked in the past but I stopped; or no, I have never smoked) were classified as current non-smokers.

\section{Statistical analysis}

Descriptive characteristics in the sample were analysed by country and by sex. Crude associations between exposure variables (ER ratio and OC) and HDI were not very different across country-specific strata and across sex-specific strata 
( $P$ for heterogeneity $>0 \cdot 1$ ). Data for three countries were pooled for further analyses, but men and women were analysed separately in line with most previous studies examining the effects of work stress on health behaviours and diet ${ }^{(5-8)}$.

Binary logistic regression was used to assess the associations between exposure variables and eight HDI components (dichotomous outcomes), respectively, after adjustment for confounders and potential mediators. OR represents the odds of an outcome occurring (e.g. healthy intake) given the exposure, compared with the odds of the outcome occurring in the absence of that exposure. For continuous exposures (ER ratio and OC), OR per unit is the odds of having healthy intake of the HDI component for a 1-unit increase in the exposure; OR per standard deviation is the odds of having healthy intake of the HDI component for a 1-sD increase in the exposure.

The associations between exposure variables and HDI (a continuous outcome) were evaluated by linear regression with the following four steps: these associations were adjusted for confounders and ER ratio in model 1, adjusted for confounders and $\mathrm{OC}$ in model 2, adjusted for confounders, ER ratio and OC in model 3 and additionally adjusted for potential mediators (depression, problem drinking and current smoker) in model 4. The $\beta$-coefficient reflects the change in the outcome for a 1-unit increase in the exposure. Standardised $\beta$-coefficient reflects the change of standard deviation in the outcome for a 1 -SD increase in the exposure; the same standardised units allow for comparing relative strength between different exposure variables. For model fit, $R^{2}$ explains how much of variation of the outcome is explained by independent variables in the model.

To evaluate the modifying role of OC in ERI-HDI relationships, linear regression was conducted for HDI regressed by OC, ER ratio and the interaction term between $\mathrm{OC}$ and $\mathrm{ER}$ ratio after adjustment for confounders and mediators. By comparing log-likelihoods of the models with and without this interaction term, likelihood ratio (LR) test was adopted to test the significance of the interaction term. All the analyses were conducted using STATA 12 software (StataCorp LP)

\section{Results}

In this sample of 6340 men and 5792 women, the mean age was 55.0 (SD 6.0) years in men and 53.0 (SD 5.3) years in women. Descriptive statistics for confounders and mediators are presented by country and by sex in Table 2 .

Table 3 shows the descriptive characteristics of dietary outcomes by country and by sex. The means of overall HDI scores were the highest in the Czech Republic and lowest in Poland in both men and women. By comparing the percentages of total energy in Table 3 with the WHO-recommended ranges in Table $1,<10 \%$ of the subjects consumed WHO-suggested ranges of SFA and free sugars; most of them consumed too much. Only $10-20 \%$ of the subjects met the WHO-recommended ranges of total carbohydrates and proteins; most of them consumed too little total carbohydrates but consumed too much proteins.

In Table 4, logistic regression was used to assess the associations between ERI and eight HDI components, respectively, after adjustment for confounders and mediators. In men, higher ER ratio was marginally and significantly $(P<0 \cdot 1)$ associated with less healthy intakes of free sugars and cholesterol. In women, higher ER ratio was significantly $(P<0.05)$ related to less healthy intakes of SFA and NSP. For example, OR of having healthy intake of SFA was $0.84(P=0.019)$ for a 1 -SD $(0.25)$ increase in ER ratio in women.

The associations between OC and eight HDI components after adjustment for confounders and mediators were evaluated by logistic regression (Table 4). In men, higher OC was at least marginally and significantly $(P<0 \cdot 1)$ associated with less healthy intakes of SFA, PUFA, free sugars and fruits and vegetables. In women, higher OC is at least marginally and significantly associated with less healthy intakes of SFA, PUFA and NSP. For instance, OR of having healthy intake of PUFA was 0.90 $(P=0.005)$ for a 1 -SD (3.56) increase in OC in women.

In Table 5, linear regression was used to assess the associations between exposure variables and HDI. In model 1 (adjusted for confounders and ER ratio), for a 1-SD increase in ER ratio, HDI decreased by 0.052 (standardised $\beta$ ) and $0.042 \mathrm{SD}$ in men and women, respectively. In model 2 (adjusted for confounders and OC), for a 1-SD increase in OC, HDI decreased by 0.056 and 0.052 $\mathrm{SD}$ in men and women, respectively. In model 3 (adjusted for confounders, ER ratio and OC) and model 4 (additionally adjusted for mediators), the ERI-HDI associations and OC-HDI associations attenuated substantially but remained significant $(P<0 \cdot 05)$. For example, in men, standardised $\beta$-coefficients for ERI-HDI associations were $-0.052,-0.039$ and -0.030 in model 1,3 and 4 , respectively, and standardised $\beta$-coefficients for OC-HDI associations were $-0.056,-0.044$ and -0.036 in model 2,3 and 4 , respectively.

In model 4 , for a 1 -SD increase in ER ratio, HDI reduced by 0.030 and $0.033 \mathrm{SD}$ in men and women, respectively. For a 1-SD increase in OC, HDI reduced by 0.036 and 0.032 SD in men and women, respectively. When effort and reward subscales were entered separately into the regression model, effort was negatively associated with HDI in men (standardised $\beta=-0.027$, $P=0.079$ ) and women (standardised $\beta=-0.036, \quad P=0.025$ ); reward was positively associated with HDI in men (standardised $\beta=0.058, P<0.001$ ) but not in women (standardised $\beta=0.017$, $P=0 \cdot 252$ ).

The associations of confounders and mediators with HDI in model 4 are shown in Table 5 . In men, divorced or widowed, manual workers, high deprivation, problem drinking and current smoker were associated with low HDI $(P<0.1)$. In women, young age, high deprivation and problem drinking were associated with low HDI.

For assessing the modifying role of OC in ERI-HDI relationships, linear regression was carried out for HDI regressed by OC, ER ratio and the interaction term between OC and ER ratio after adjustment for confounders and mediators. LR test showed that the interaction term was non-significant in men $(P=0 \cdot 219)$ and women $(P=0 \cdot 431)$

\section{Discussion}

To our knowledge, this large cross-sectional survey of CEE populations was the first study to provide evidence for the links between the ERI model and a range of dietary indicators. High ER ratio and high OC personality are both associated with unhealthy diet quality; the modifying role of OC in ERI-diet relationships is 
S.-W. Chen et al.

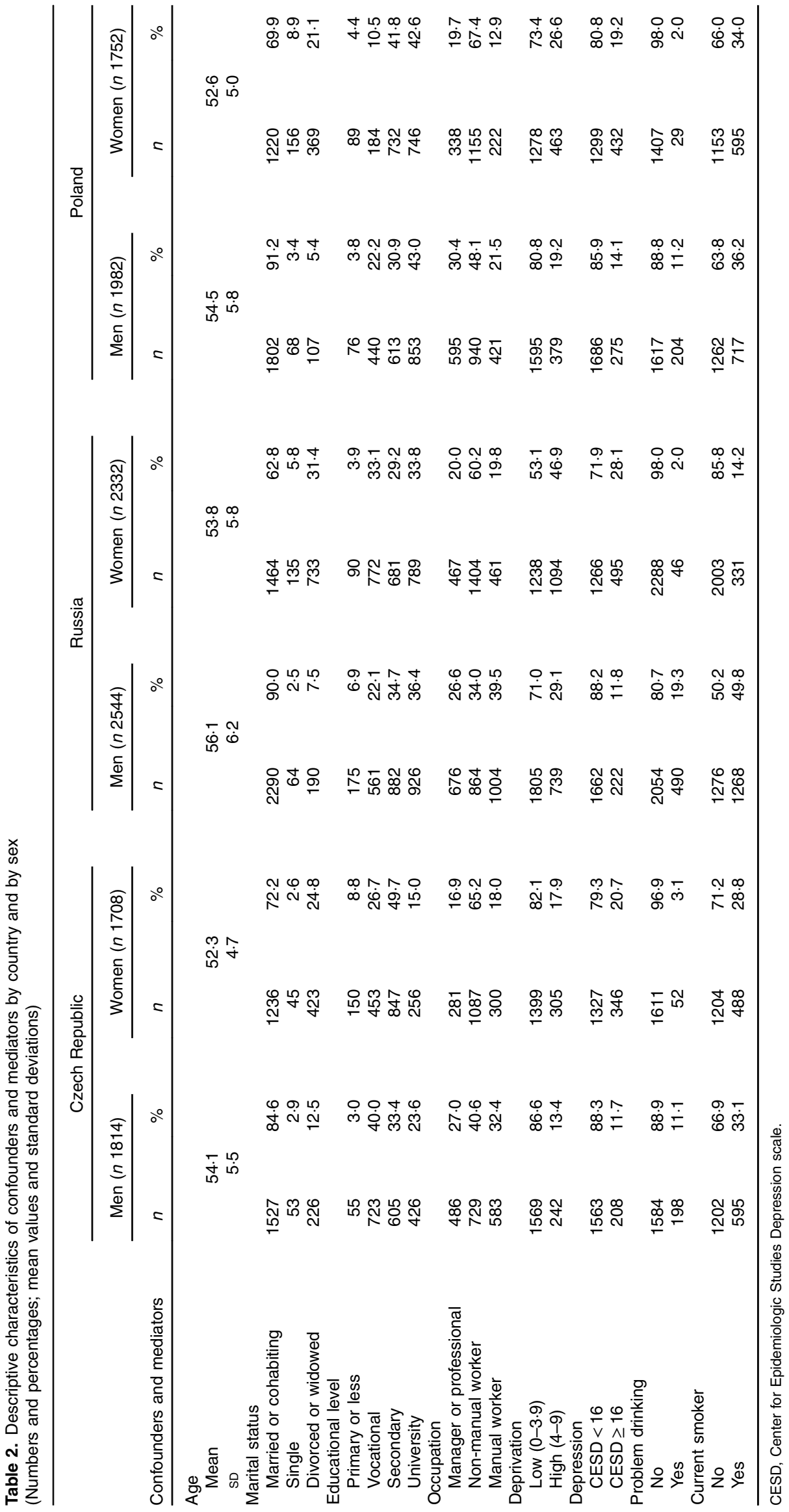


Work stress, personality and diet quality

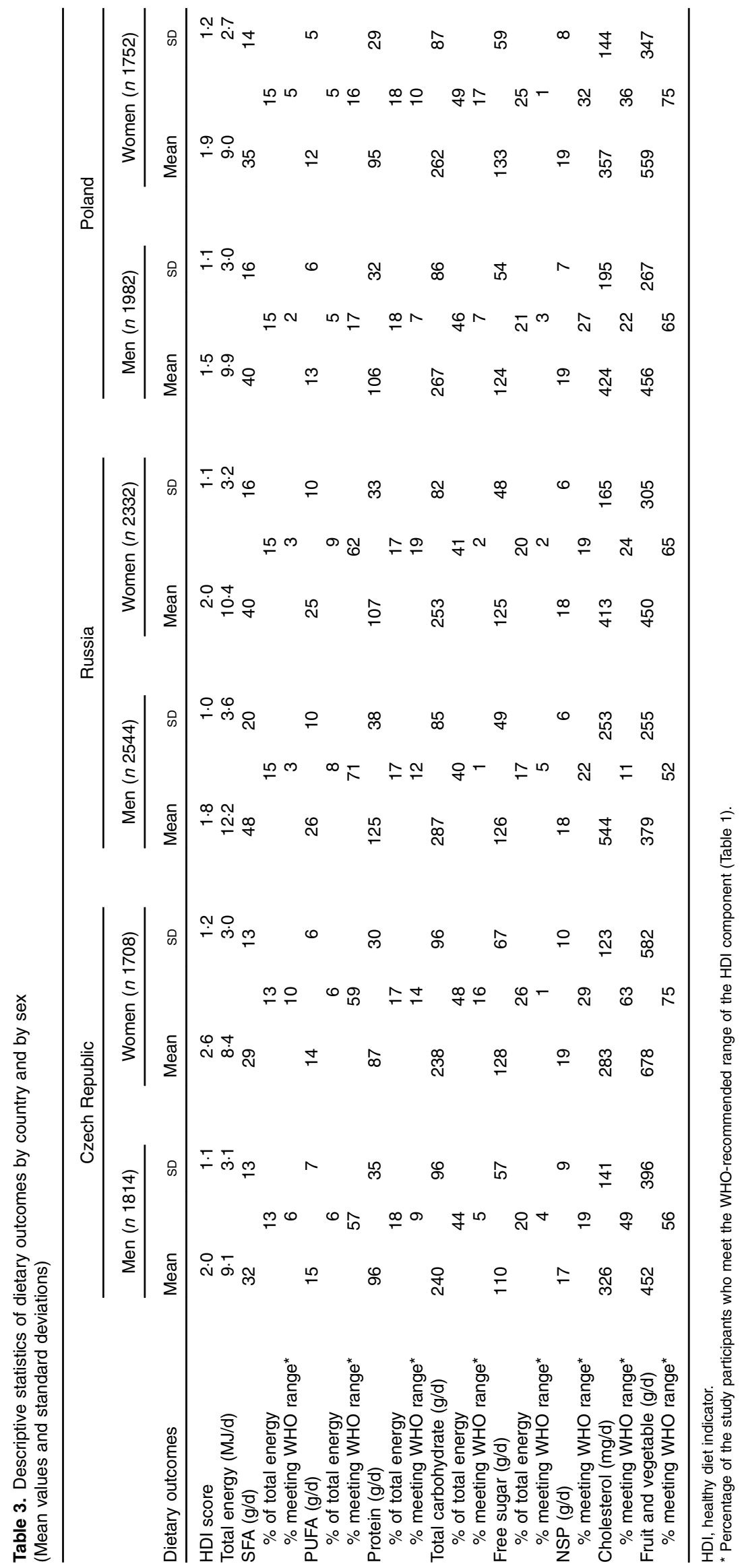


Table 4. Associations between exposure variables and eight HDI components by logistic regression (Odds ratios, $95 \%$ confidence intervals and standard deviations)

\begin{tabular}{|c|c|c|c|c|c|c|c|c|}
\hline \multirow[b]{2}{*}{ Eight HDI components } & \multicolumn{2}{|c|}{ Men $(n$ 6340) } & \multirow[b]{2}{*}{ OR per sD $†$} & \multirow[b]{2}{*}{$P$} & \multicolumn{2}{|c|}{ Women ( $n$ 5792) } & \multirow[b]{2}{*}{ OR per sD $†$} & \multirow[b]{2}{*}{$P$} \\
\hline & OR per unit* & $95 \% \mathrm{Cl}$ & & & OR per unit* & $95 \% \mathrm{Cl}$ & & \\
\hline \multicolumn{9}{|c|}{ 1. Association between ER ratio and diet after adjustment for $\mathrm{OC}$, confounders and mediators $\ddagger$} \\
\hline SFA & 0.71 & $0.35,1.46$ & 0.92 & 0.349 & 0.51 & $0.30,0.89$ & 0.84 & 0.019 \\
\hline PUFA & 0.84 & $0.65,1.08$ & 0.95 & 0.151 & 1.01 & $0.78,1.32$ & 1.00 & 0.893 \\
\hline Protein & 0.89 & $0.59,1.35$ & 0.97 & 0.594 & 0.82 & $0.57,1.18$ & 0.95 & 0.301 \\
\hline Total carbohydrate & 0.89 & $0.51,1.54$ & 0.97 & 0.671 & 0.76 & $0.51,1.14$ & 0.93 & $0 \cdot 183$ \\
\hline Free sugars & 0.60 & $0.34,1.05$ & 0.87 & 0.098 & 0.65 & $0.30,1.22$ & 0.90 & 0.496 \\
\hline NSP & 0.91 & $0.69,1.21$ & 0.97 & 0.513 & 0.73 & $0.55,0.98$ & 0.92 & 0.033 \\
\hline Cholesterol & 0.82 & $0.63,1.05$ & 0.93 & 0.095 & 0.88 & $0.68,1.13$ & 0.97 & 0.329 \\
\hline Fruit and vegetable & 0.83 & $0.66,1.06$ & 0.95 & 0.116 & 0.86 & $0.66,1.12$ & 0.96 & 0.273 \\
\hline \multicolumn{9}{|c|}{ 2. Association between $\mathrm{OC}$ and diet after adjustment for ER ratio, confounders and mediators } \\
\hline SFA & 0.95 & $0.90,0.99$ & 0.84 & 0.043 & 0.96 & $0.93,1.01$ & 0.88 & 0.099 \\
\hline PUFA & 0.97 & $0.95,0.99$ & 0.92 & 0.020 & 0.97 & $0.95,0.99$ & 0.90 & 0.005 \\
\hline Protein & 1.00 & $0.97,1.03$ & 1.01 & 0.862 & 0.98 & $0.96,1.01$ & 0.95 & 0.290 \\
\hline Total carbohydrate & 0.98 & $0.94,1.03$ & 0.96 & 0.569 & 0.99 & $0.96,1.02$ & 0.97 & 0.554 \\
\hline Free sugars & 0.96 & $0.92,1.00$ & 0.87 & 0.061 & 0.96 & $0.89,1.04$ & 0.88 & 0.294 \\
\hline NSP & 0.98 & $0.96,1.01$ & 0.95 & 0.148 & 0.98 & $0.96,1.00$ & 0.93 & 0.072 \\
\hline Cholesterol & 0.99 & $0.97,1.01$ & 0.97 & 0.466 & 1.00 & $0.98,1.02$ & 0.99 & 0.943 \\
\hline Fruit and vegetable & 0.98 & $0.96,1.00$ & 0.94 & 0.079 & 0.99 & $0.97,1.01$ & 0.98 & 0.585 \\
\hline
\end{tabular}

$\mathrm{HDI}$, healthy diet indicator; ER, effort:reward; OC, over-commitment.

* OR per unit is the odds of having healthy intake of the HDI component for a 1-unit increase in the exposure.

† OR per sD is the odds of having healthy intake of the HDI component for a 1 -sD increase in the exposure. 1 sD of ER ratio $=0.25$ in men and women. 1 sD of $\mathrm{OC}=3.65$ in men and 3.56 in women.

‡ Logistic regression was used to assess the associations between exposure variables (ER ratio and OC) and eight HDI components, respectively, after adjustment for confounders and mediators.

non-significant. This study provides additional evidence for the potential role of OC in ERI-Outcome associations, an area where current literature is not entirely consistent.

\section{Associations between effort-reward imbalance and diet quality}

Our results found inconsistent effects of ERI on individual HDI components, probably reflecting sex or individual differences in dietary responses to work stress ${ }^{(42)}$. Higher ER ratio was associated with less healthy intakes of free sugars and cholesterol in men; higher ER ratio was related to less healthy intakes of SFA and NSP in women (Table 4). However, overall impacts of ERI on HDI appeared robust; for a 1-SD increase in ER ratio, HDI reduced by 0.030 and $0.033 \mathrm{sD}$ in men and women, respectively (Table 5).

These findings imply that work stress defined by the ER ratio is associated with people's choice of overall diet quality, which is linked to risks of chronic diseases. There are at least two potential mechanisms linking work stress to diet based on existing evidence. In biological pathways, work stress can influence an individual's physiological responses (e.g. increased activities of the hypothalamus-pituitary-adrenal axis and elevated levels of cortisol and insulin), resulting in food choice towards high-fat and high-carbohydrate content ${ }^{(4)}$. In psychological pathways, work stress (viewed as primary cognitive appraisal, perception of severity of the threat) can affect one's problem-focused or emotion-focused coping. Engaging in risky health behaviour is an emotion-focused coping, which temporarily relieves psychological distress and distracts attention from stressful situation ${ }^{(43)}$.
In addition, our finding provided evidence supporting that the effect of ERI on diet might be partially mediated by depression, alcohol drinking and smoking, as the ERI-diet associations were substantially reduced after adjustment for these mediators. Evidence reported that high ER ratio predicted depression ${ }^{(34)}$, alcohol drinking ${ }^{(16)}$ and smoking ${ }^{(17)}$, all of which may influence diet via mechanisms such as overeating or restraint from eating ${ }^{(37-39)}$. In fact, direct evidence showed that high ER ratio was associated with over-eating in obese men in Japan ${ }^{(44)}$. The British Whitehall II cohort study found that work stress predicted increased body weight in obese men, but reduced body weight in thin men; no corresponding effects were reported in women ${ }^{(45)}$.

Despite existing evidence on the link between the DC model and diet, our findings on ERI-diet associations might strengthen the knowledge gap due to the advantage of the ERI model. The DC model reflected social concerns on industrial workers' control in the $1970^{(46)}$. The diminished industrial setting of working environments might reduce the prevalence of this exposure ${ }^{(47)}$. In this era of globalisation, tight managerial control is shifted to flexibility, self-regulation and decentralisation. The ERI model emphasising psychosocial reward in career prospect, self-esteem and job security might be more sensitive in explaining the nature of work stress in modern occupations ${ }^{(48)}$.

\section{Associations between over-commitment and diet quality}

Our results found that higher OC was significantly associated with lower HDI. OC reflects a cognitive motivational pattern characterised by high need for control, excessive striving at work and inability to withdraw from work. Siegrist initially developed $\mathrm{OC}$ as a distinct individual pattern of coping with 
Table 5. Associations between exposure variables and HDI by linear regression ( $\beta$ Values)

\begin{tabular}{|c|c|c|c|c|c|c|}
\hline \multirow[b]{2}{*}{ Variables } & \multicolumn{3}{|c|}{ Men $(n 6340)$} & \multicolumn{3}{|c|}{ Women (n 5792) } \\
\hline & $\beta^{*}$ & Standardised $\beta \dagger$ & $P$ & $\beta^{*}$ & Standardised $\beta \dagger$ & $P$ \\
\hline \multicolumn{7}{|c|}{ Model 1: adjusted for confounders and ER ratio } \\
\hline $\begin{array}{l}\text { ER ratio } \\
\text { Model fit }\end{array}$ & -0.224 & $\begin{array}{r}-0.052 \\
R^{2} 0.045\end{array}$ & $<0.001$ & -0.198 & $\begin{array}{r}-0.042 \\
R^{2} 0.082\end{array}$ & 0.002 \\
\hline \multicolumn{7}{|c|}{ Model 2: adjusted for confounders and OC } \\
\hline $\begin{array}{l}\text { OC } \\
\text { Model fit } ¥\end{array}$ & $-0 \cdot 017$ & $\begin{array}{r}-0.056 \\
R^{2} 0.045\end{array}$ & $<0.001$ & -0.017 & $\begin{array}{r}-0.052 \\
R^{2} 0.081\end{array}$ & $<0.001$ \\
\hline \multicolumn{7}{|c|}{ Model 3: adjusted for confounders, ER ratio and OC } \\
\hline $\begin{array}{l}\text { ER ratio } \\
\text { OC } \\
\text { Model fit } \ddagger\end{array}$ & $\begin{array}{l}-0.169 \\
-0.013\end{array}$ & $\begin{array}{r}-0.039 \\
-0.044 \\
R^{2} 0.046\end{array}$ & $\begin{array}{l}0.005 \\
0.002\end{array}$ & $\begin{array}{l}-0.171 \\
-0.014\end{array}$ & $\begin{array}{r}-0.037 \\
-0.043 \\
R^{2} 0.082\end{array}$ & $\begin{array}{l}0.017 \\
0.003\end{array}$ \\
\hline \multicolumn{7}{|c|}{ Model 4: additionally adjusted for potential mediators } \\
\hline $\begin{array}{l}\text { ER ratio } \\
\text { OC }\end{array}$ & $\begin{array}{l}-0.126 \\
-0.011\end{array}$ & $\begin{array}{l}-0.030 \\
-0.036\end{array}$ & $\begin{array}{l}0.046 \\
0.015\end{array}$ & $\begin{array}{l}-0.153 \\
-0.011\end{array}$ & $\begin{array}{l}-0.033 \\
-0.032\end{array}$ & $\begin{array}{l}0.036 \\
0.040\end{array}$ \\
\hline \multicolumn{7}{|l|}{ Confounders } \\
\hline $\begin{array}{l}\text { Age } \\
\text { Marital status: married }\end{array}$ & 0.004 & 0.021 & $0 \cdot 124$ & 0.011 & 0.050 & 0.001 \\
\hline $\begin{array}{l}\text { Single } \\
\text { Divorced or widowed }\end{array}$ & $\begin{array}{r}0.085 \\
-0.084\end{array}$ & $\begin{array}{r}0.013 \\
-0.022\end{array}$ & $\begin{array}{l}0.346 \\
0.098\end{array}$ & $\begin{array}{r}0.086 \\
-0.042\end{array}$ & $\begin{array}{r}0.017 \\
-0.016\end{array}$ & $\begin{array}{l}0.236 \\
0.301\end{array}$ \\
\hline \multicolumn{7}{|l|}{ Education: primary/less } \\
\hline Vocational & 0.052 & 0.021 & 0.541 & 0.078 & 0.028 & 0.346 \\
\hline Secondary & 0.008 & 0.004 & 0.921 & 0.052 & 0.021 & 0.519 \\
\hline University & 0.078 & 0.034 & 0.360 & 0.138 & 0.054 & 0.101 \\
\hline \multicolumn{7}{|l|}{ Occupation: manager } \\
\hline Non-manual worker & -0.032 & -0.014 & 0.446 & -0.002 & -0.001 & 0.969 \\
\hline Manual worker & -0.070 & -0.032 & 0.042 & 0.027 & 0.008 & 0.655 \\
\hline \multicolumn{7}{|l|}{ Deprivation: low } \\
\hline High & -0.066 & -0.024 & 0.084 & -0.102 & -0.039 & 0.008 \\
\hline \multicolumn{7}{|l|}{ Potential mediators } \\
\hline Depression: Yes & -0.027 & -0.008 & 0.552 & -0.021 & -0.008 & 0.606 \\
\hline Problem drinking: Yes & -0.194 & -0.062 & $<0.001$ & -0.264 & -0.035 & 0.014 \\
\hline $\begin{array}{l}\text { Current smoker: Yes } \\
\text { Model fit }\end{array}$ & $-0 \cdot 192$ & $\begin{array}{r}-0.086 \\
R^{2} 0.063\end{array}$ & $<0.001$ & -0.048 & $\begin{array}{r}-0.018 \\
R^{2} 0.087\end{array}$ & 0.225 \\
\hline
\end{tabular}

$\mathrm{HDI}$, healthy diet indicator; ER ratio, effort:reward ratio; OC, over-commitment.

* $\beta$-Coefficient reflects the change in HDI score for a 1-unit increase in the exposure.

† Standardised $\beta$-coefficient reflects the change of standard deviation in the HDI score for a 1 -SD increase in the exposure. 1 SD of ER ratio $=0.25$ in men and women. 1 SD of $\mathrm{OC}=3.65$ in men and 3.56 in women. $1 \mathrm{SD}$ of $\mathrm{HDI}=1.08$ in men and 1.18 in women.

$\ddagger R^{2}$ explains how much of variation of $\mathrm{HDI}$ score (outcome) is explained by independent variables in the model.

work demands (need for control), which evolved from Type A behaviour (characterised by hostility, aggression, urgency, competitiveness and hard driving) ${ }^{(49)}$. Type A persons have high need for control over environments and tend to feel loss of control; their coping response is to assert control over environments ${ }^{(50)}$.

Very little literature is available on the potential role of OC in relationships between ERI and health behaviours; two studies reported no main effect of OC on smoking without examining the modifying effect of $\mathrm{OC}^{(21,22)}$. This study is probably the first to support the main effect of OC on health behaviours (diet), and the modifying role of $\mathrm{OC}$ is non-significant. However, the effect of OC on diet may be somewhat supported by previous studies demonstrating the impact of Type A behaviour (or its component hostility) on health behaviours ${ }^{(51)}$. For example, Type A behaviour was associated with high consumption of SFA, cholesterol and vegetables in a cohort study of 10602 men in Northern Ireland and France ${ }^{(52)}$.

Our results reported that the OC-HDI associations attenuated after adjustment for ER ratio (comparison of standardised $\beta$ between model 2 and 3 in Table 5), suggesting that the effect of OC on HDI might be mediated or confounded by ERI.
Type A behaviour at adolescence was found to predict high ER ratio at adulthood ${ }^{(53)}$. Personality may influence work stress via cognitive behavioural mechanisms: selection (e.g. Type A persons select themselves into highly competitive tasks), perception (e.g. Type A persons tend to perceive high levels of work stress) and stressor creation (e.g. Type A persons create work stressors for themselves by provoking interpersonal conflict $)^{(54)}$. Thus, it is likely that high OC affects high ER ratio, which results in low HDI. If ERI is considered a mediator in the OC-HDI causal path, it would not be viewed as a confounder ${ }^{(35)}$.

On the other hand, our results found that the ERI-HDI associations were reduced after adjustment for OC (comparison of standardised $\beta$ between model 1 and 3 in Table 5), suggesting that the effect of ERI on HDI might be mediated or confounded by OC. In contrast to classical perspective suggesting that personalities do not change, the meta-analysis found that personality continues to change moderately throughout adulthood ${ }^{(55)}$. Work stress was found to induce changes in personality ${ }^{(56)}$. Thus, it might be plausible that high ER ratio affects high OC, which then influences low HDI. 
By the life course approach, there might be a 'bidirectional' relationship between personality (OC) and work environment (ERI) across life span; personality can shape work experience, and work experience may have an impact on personality ${ }^{(57)}$.

\section{Methodological issues}

Several methodological issues should be considered when interpreting our results. First, FFQ is the primary method to gather dietary information from large population samples, as it is inexpensive and representative of average long-term diet. However, the FFQ method tends to be semi-quantitative rather than fully quantitative, probably resulting in overestimation or underestimation of dietary intakes ${ }^{(58)}$. Thus, assigning HDI scores may be imprecise and may introduce some misclassification, but the ranking of subjects in terms of HDI should be unbiased.

Second, the validity of the FFQ regarding fruit, vegetable and micronutrient intakes was found acceptable by estimating correlations with plasma biomarkers in a random subsample of the HAPIEE study ${ }^{(59)}$. Nevertheless, other HDI components have not been tested for validity. Third, the HDI was constructed by Huijbregts' original approach (HDI components coded as dichotomous variables). However, Jankovic et al. ${ }^{(3)}$ proposed a new HDI approach, which applied continuous scoring to obtain greater variation between individuals, and it may provide more precise estimation of diet quality.

Fourth, a cross-sectional study often has difficulty in determining the time order between the exposure and the outcome. Reverse causality that unhealthy diet may cause high levels of work stress cannot be ruled out. Although less likely than the other causal direction, poor diet may elicit physiological (e.g. pro-inflammatory state) and psychological problems (e.g. depression) ${ }^{(60)}$, which may render persons more sensitive to work stress. Moreover, the cross-sectional design does not allow identification of the causal chains between OC, ERI and diet; a future cohort study is needed in order to draw firm conclusions on the relationships.

Fifth, although potential confounders were adjusted for in our analyses, there may be residual confounders not taken into account, leading to underestimation or overestimation of the exposure-outcome relationships. For example, chronic stressors outside workplace (e.g. work-family conflicts or family stressors) were known risk factors for unhealthy diet but were unavailable in the HAPIEE study ${ }^{(61)}$.

Finally, it is unclear to what extent our findings can be generalised beyond these study samples covering urban populations in the Czech Republic, Russia and Poland; however, socio-economic and health indicators suggest that these study populations approximately represent their national populations. Evidence shows that the effects of ERI on self-rated health and alcohol drinking in CEE are not very different from those found in Western Europe ${ }^{(28,62)}$. As evidence for the ERI-diet association is still lacking in existing literature, our findings may have the potential to be generalised to the European populations.

\section{Implications for practice and policy}

Workplace has emerged as an important environment for delivering behaviour change interventions targeted at diet, smoking and physical activity. Workplace may offer healthy food served at cafeterias and education on healthy diet. Sorenson et al. ${ }^{(63)}$ integrated intervention to reduce exposure to occupational hazards with intervention to improve health behaviours; the rate of behaviour changes in the integrated programme was twice as high as that focusing on health behaviours only. As the effect of work stress on diet was found in this study, organisational interventions should address potential occupational hazards - work stress.

The strategy of organisational interventions based on the ERI model is to restore the balance between extrinsic effort and reward at work. In terms of extrinsic effort, interventions can focus on reduction of overtime work, even distribution of workload and responsibility and provision of holidays. In terms of reward, social skill training improves a supervisor's leadership behaviours, resulting in increased esteem reward. Introduction of additional benefits can increase non-monetary reward. Provision of vocational training and steps for promotion can ensure employees' job security ${ }^{(64)}$.

The association between OC personality and diet was found in our study. A meta-analysis from thirty-six studies found that individual interventions based on cognitive behaviour therapy produced larger effects than others ${ }^{(65)}$. It is plausible to suggest targeting cognitive behaviour mechanisms via which personality can influence health behaviours. For example, Aust et al. ${ }^{(66)}$ conducted an intervention to improve adverse effects of OC; this programme included self-observation for perception of arousal, relaxation training, management of conflict and coping with anger. Limm et al. ${ }^{(67)}$ conducted a group prevention programme to foster awareness of stress situations based on the ERI model and to provide coping strategies with stressful situations; the programme reduced perceived stress reactivity, sympathetic activation and ER ratio. Although it is difficult to induce strong changes in personality itself, to change an individual's tendency in cognition and behaviour appears practical.

Our finding of potentially bidirectional relationships between ERI and OC implies that interventions can focus on both working environments and individuals in order to disrupt cumulated effects in the reciprocal relations. Individual interventions are effective at individual-level outcomes such as health behaviours, but organisational interventions have positive impacts on organisational-level outcomes such as reducing exposure to work stressors. Superior results would be expected from combining individual and organisational interventions (a multi-level perspective) over a single type ${ }^{(68)}$. Organisational interventions for work stress and health behaviours can be implemented if resources are available; individual interventions for people vulnerable to work stress can be adopted according to individual needs.

\section{Acknowledgements}

The authors thank researchers, interviewers and participants of the HAPIEE study from six towns in the Czech Republic, Novosibirsk in Russia and Krakow in Poland.

The HAPIEE study was supported by the Wellcome Trust (grant numbers WT064947, WT081081); the US National Institute of Aging 
(grant number 1RO1AG23522); and the MacArthur Foundation (Initiative on Social Upheaval and Health). These funders had no role in the design, analysis or writing of this article.

The authors' contributions are as follows: S.-W. C., A. Peasey and H. P. contributed to formulating the research questions, analysing the data and writing the article. D. S. and J.-H. C. contributed to critically revising the article for important content. M. B., S. M., A. Pajak and R. K. contributed to the study design and the data collection in three countries. All authors read and approved the final version of the manuscript.

The authors declare that there are no conflicts of interest.

\section{References}

1. Marmot M, Smith GD, Stansfeld S, et al. (1991) Health inequalities among British Civil servants: the Whitehall II study. Lancet 337, 1387-1393.

2. Luepker RV \& Lakshminarayan K (2009) Cardiovascular and cerebrovascular diseases. In Oxford Textbook of Public Health, 5th ed. pp. 971-996 [R Detels, R Beaglehole, MA Lansang and M Gulliford, editors]. Oxford: Oxford University Press.

3. Jankovic N, Geelen A, Streppel MT, et al. (2014) Adherence to a healthy diet according to the World Health Organization guidelines and all-cause mortality in elderly adults from Europe and the United States. Am J Epidemiol 180, 978-988.

4. Newman E, O'Connor DB \& Conner M (2007) Daily hassles and eating behaviour: the role of cortisol reactivity status. Psychoneuroendocrinology 32, 125-132.

5. Lallukka T, Lahelma E, Rahkonen O, et al. (2008) Associations of job strain and working overtime with adverse health behaviors and obesity: evidence from the Whitehall II Study, Helsinki Health Study, and the Japanese Civil Servants Study. Soc Sci Med 66, 1681-1698.

6. Lallukka T, Sarlio-Lähteenkorva S, Roos E, et al. (2004) Working conditions and health behaviours among employed women and men: the Helsinki Health Study. Prev Med 38, 48-56.

7. Hellerstedt WL \& Jeffery RW (1997) The association of job strain and health behaviours in men and women. Int J Epidemiol 26, 575-583.

8. Kawakami N, Tsutsumi A, Haratani T, et al. (2006) Job strain, worksite support, and nutrient intake among employed Japanese men and women. J Epidemiol 16, 79-89.

9. Heikkilä K, Nyberg ST, Fransson EI, et al. (2012) Job strain and alcohol intake: a collaborative meta-analysis of individualparticipant data from 140000 men and women. PLOS ONE 7, e40101.

10. Heikkilä K, Nyberg ST, Fransson EI, et al. (2012) Job strain and tobacco smoking: an individual-participant data meta-analysis of 166130 adults in 15 European studies. PLOS ONE 7, e35463.

11. Fransson EL, Heikkilä K, Nyberg ST, et al. (2012) Job strain as a risk factor for leisure-time physical inactivity: an individualparticipant meta-analysis of up to 170,000 men and women. Am J Epidemiol 176, 1078-1089.

12. Kivimäki M, Päivi LA, Luukkonen R, et al. (2002) Work stress and risk of cardiovascular mortality: prospective cohort study of industrial employees. BMJ 325, 857-860.

13. Van Vegchel N, De Jonge J, Bosma H, et al. (2005) Reviewing the effort-reward imbalance model: drawing up the balance of 45 empirical studies. Soc Sci Med 60, 1117-1131.

14. Kumari M, Head J \& Marmot M (2004) Prospective study of social and other risk factors for incidence of type 2 diabetes in the Whitehall II study. Arch Int Med 164, 1873-1880.

15. Siegrist J (1996) Adverse health effects of high effort-low reward conditions at work. J Occup Health Psychol 1, 27-41.
16. Head J, Stansfeld SA \& Siegrist J (2004) The psychosocial work environment and alcohol dependence: a prospective study. Occup Environ Med 61, 219-224.

17. Kouvonen A, Kivimäki M, Virtanen M, et al. (2005) Work stress, smoking status, and smoking intensity: an observational study of 46190 employees. J Epidemiol Community Health 59, 63-69.

18. Kouvonen A, Kivimäki M, Elovainio M, et al. (2006) Effort-reward imbalance and sedentary lifestyle: an observational study in a large occupational cohort. Occup Environ Med 63, 422-427.

19. Siegrist J, Starke D, Chandola T, et al. (2004) The measurement of effort-reward imbalance at work: European comparisons. Soc Sci Med 58, 1483-1499.

20. Andreassen CS, Griffiths MD, Hetland J, et al. (2014) The prevalence of workaholism: a survey study in a nationally representative sample of Norwegian employees. PLOS ONE 9, e102446.

21. Ota A, Masue T, Yasuda N, et al. (2010) Psychosocial job characteristics and smoking cessation: a prospective cohort study using the demand-control-support and effort-reward imbalance job stress models. Nicotine Tob Res 12, 287-293.

22. Radi S, Ostry A \& LaMontagne AD (2007) Job stress and other working conditions: relationships with smoking behaviors in a representative sample of working Australians. Am J Ind Med 50, 584-596.

23. Boylan S, Welch A, Pikhart H, et al. (2009) Dietary habits in three Central and Eastern European countries: the HAPIEE study. BMC Public Health 9, 439-452.

24. Bobak M \& Marmot M (1996) East-West mortality divide and its potential explanations: proposed research agenda. BMJ 312, 421-425.

25. Laszlo KD, Pikhart H, Kopp MS, et al. (2010) Job insecurity and health: a study of 16 European countries. Soc Sci Med 70, 867-874.

26. Bobak M, Hertzman C, Skodova Z, et al. (1998) Association between psychosocial factors at work and non-fatal myocardial infarction in a population based case-control study in Czech men. Epidemiology 9, 43-47.

27. Pikhart H, Bobak M, Siegrist J, et al. (2001) Psychosocial work characteristics and self-rated health in four post-communist countries. J Epidemiol Community Health 55, 624-630.

28. Bobak M, Pikhart H, Kubinova R, et al. (2005) The association between psychosocial characteristics at work and problem drinking: a cross-sectional study of men in three Eastern European urban populations. Occup Environ Med 62, 546-550.

29. Peasey A, Bobak M, Kubinova R, et al. (2006) Determinants of cardiovascular disease and other non-communicable diseases in Central and Eastern Europe: rationale and design of the HAPIEE study. BMC Public Health 6, 255-264.

30. Willett W, Sampson L, Stampfer MJ, et al. (1985) Reproducibility and validity of a semi-quantitative food frequency questionnaire. Am J Epidemiol 122, 51-65.

31. McCance R \& Widdowson E (2002) McCance \& Widdowson's the Composition of Foods: Summary Edition. Cambridge: Royal Society of Chemistry.

32. World Health Organization (2003) Diet, Nutrition and the Prevention of Chronic Diseases. Joint WHO/FAO Expert Consultation. WHO Technical Report Series no. 916. Geneva: WHO.

33. Huijbregts P, Feskens E, Rasanen L, et al. (1997) Dietary pattern and 20 year mortality in elderly men in Finland, Italy, and Netherlands: longitudinal cohort study. BMJ 315, 13-17.

34. Pikhart H, Bobak M, Pajak A, et al. (2004) Psychosocial factors at work and depression in three countries of Central and Eastern Europe. Soc Sci Med 58, 1475-1482.

35. Rothman KJ, Greenland S \& Lash TL (2008) Modern Epidemiology, 3rd ed. Philadelphia, PA: Lippincott Williams \& Wilkins. 
36. Maguire ER \& Monsivais P (2015) Socio-economic dietary inequalities in UK adults: an updated picture of key food groups and nutrients from national surveillance data. BrJ Nutr 113, 181-189.

37. Markowitz S, Friedman MA \& Arent SM (2008) Understanding the relation between obesity and depression: causal mechanisms and implications for treatment. Clin Psychol Sci $\operatorname{Prac}$ 15, 1-20.

38. Sinha R \& O'Malley SS (2000) Alcohol and eating disorders: implications for alcohol treatment and health services research. Alcohol Clin Exp Res 24, 1312-1319.

39. Perkins KA (1992) Effects of tobacco smoking on caloric intake. Br J Addict 87, 193-205.

40. Radloff LS (1977) The CES-D scale: a self-report depression scale for research in the general population. Appl Psychol Meas 1, 385-401.

41. Rush AJ, Pincus HA \& First MB (2009) Handbook of Psychiatric Measures. Washington, DC: American Psychiatric Association.

42. Willett W (2013) Nutritional Epidemiology, 3rd ed. New York, NY: Oxford University Press.

43. Wiebe DJ \& Fortenberry KT (2006) Mechanisms relating personality and health. In Handbook of Personality and Health, pp. 137-156 [ME Vollrath, editor]. Chichester: John Wiley \& Sons.

44. Takaki J, Minoura A, Irimajiri H, et al. (2010) Interactive effects of job stress and body mass index on over-eating. $J$ Occup Health 52, 66-73.

45. Kivimäki M, Head J, Ferrie J, et al. (2006) Work stress, weight gain and weight loss: evidence for bidirectional effects of job strain on body mass index in the Whitehall II study. Int J Obes (Lond) 30, 982-987.

46. Johnson J (2008) Globalization, workers' power and the psychosocial work environment - is the demand-controlsupport model still useful in a neoliberal era? Scand J Work Environ Health 6, 15-21.

47. Netterstrom B (2012) Job strain as a measure of exposure to psychological strain. Lancet 380, 1455-1456.

48. Calnan M, Wadsworth E, May M, et al. (2004) Job strain, effort-reward imbalance, and stress at work: competing or complementary models? Scand J Public Health 32, 84-93.

49. Siegrist J, Peter R, Junge A, et al. (1990) Low status control, high effort at work and ischemic heart disease: prospective evidence from blue-collar men. Soc Sci Med 31, 1127-1134.

50. Rosenman RH (1986) Current and past history of type A behavior pattern. In Biological and Psychological Factors in Cardiovascular Disease, pp. 15-40 [TH Schmidt, TM Dembroski and G Blumchen, editors]. Berlin: Springer.

51. Siegler IC, Peterson BL, Barefoot JC, et al. (1992) Hostility during late adolescence predicts coronary risk factors at mid-life. Am J Epidemiol 136, 146-154.

52. Appleton KM, Woodside JV, Yarnell JW, et al. (2007) Type A behaviour and consumption of an atherogenic diet: no association in the PRIME study. Appetite 49, 554-560.
53. Hintsa T, Hintsanen M, Jokela M, et al. (2010) Divergent influence of different Type A dimensions on job strain and effort-reward imbalance. J Occup Environ Med 52, 1-7.

54. Semmer NK (2006) Personality, stress, and coping. In Handbook of Personality and Health, pp. 73-114 [ME Vollrath, editor]. Chichester: John Wiley \& Sons.

55. Roberts BW \& Delvecchio WF (2000) The rank-order consistency of personality traits from childhood to old age: a quantitative review of longitudinal studies. Psychol Bull 126, $3-25$.

56. Van Aken MAG, Denissen JJA, Branje SJT, et al. (2006) Midlife concerns and short-term personality change in middle adulthood. Eur J Pers 20, 497-513.

57. Roberts BW, Caspi A \& Moffitt TE (2003) Work experiences and personality development in young adulthood. J Pers Soc Psychol 84, 582-593.

58. Cade J, Thompson R, Burley V, et al. (2002) Development, validation and utilization of food-frequency questionnaires a review. Public Health Nutr 5, 567-587.

59. Stefler D, Pikhart H, Jankovic N, et al. (2014) Healthy diet indicator and mortality in Eastern European populations: prospective evidence from the HAPIEE cohort. Eur J Clin Nutr 68, 1346-1352.

60. Suzuki T, Miyaki K, Tsutsumi A, et al. (2013) Japanese dietary pattern consistently relates to low depressive symptoms and it is modified by job strain and worksite supports. J Affect Disord 150, 490-498.

61. Roos E, Sarlio-Lähteenkorva S, Lallukka T, et al. (2007) Associations of work-family conflicts with food habits and physical activity. Public Health Nutr 10, 222-229.

62. Salavecz G, Chandola T, Pikhart H, et al. (2010) Work stress and health in Western European and post-communst countries: an East-West comparison study. J Epidemiol Community Health 64, 57-62.

63. Sorenson G, McLellan D, Dennerlein JT, et al. (2013) Integration of health protection and health promotion: rationale, indicators, and metrics. J Occup Environ Med 55, 12-18.

64. Tsutsumi A \& Kawakami N (2004) A review of empirical studies on the model of effort-reward imbalance at work: reducing occupational stress by implementing a new theory. Soc Sci Med 59, 2335-2359.

65. Richardson KM \& Rothstein HR (2008) Effects of occupational stress management intervention programs: a meta-analysis. J Occup Health Psychol 13, 69-93.

66. Aust B, Peter R \& Siegrist J (1997) Stress management in bus drivers: a pilot study based on the model of effort-reward imbalance. Int J Stress Manag 4, 297-305.

67. Limm H, Gundel H, Heinmuller M, et al. (2011) Stress management interventions in the workplace improve stress reactivity: a randomised controlled trial. Occup Environ Med 68, 126-133.

68. Okechukwu C, Davison K \& Emmons K (2014) Changing health behaviours in a social context. In Social Epidemiology, 2nd ed. pp. 365-395 [LF Berkman, I Kawachi and MM Glymour, editors]. New York, NY: Oxford University Press. 